\title{
A família Cactaceae na Bacia Hidrográfica do Rio Taquari, RS, Brasil
}

\author{
Juliane Bruxel ${ }^{1,2}$ e André Jasper ${ }^{1}$
}

Recebido em 18/03/2003. Aceito em 16/07/2004

\begin{abstract}
RESUMO- (A família Cactaceae na Bacia Hidrográfica do Rio Taquari, RS, Brasil). O levantamento das espécies da família Cactaceae na Bacia Hidrográfica do Rio Taquari, RS, Brasil foi realizado com o objetivo de conhecer a diversidade e a distribuição desta importante família botânica, uma vez que não existem dados sobre a mesma para a região. Foram encontradas 11 espécies distribuídas em cinco gêneros: Cereus hildmannianus K. Schumann, Lepismium cruciforme (Vellozo) Miquel, Lepismium warmingianum (K. Schumann) Barthlott, Lepismium houlletianum (Lemaire) Barthlott, Lepismium lumbricoides (Lemaire) Barthlott, Rhipsalis floccosa ssp. pulvinigera (G.A. Lindberg) Barthlott \& N.P. Taylor, Rhipsalis teres (Vellozo) Steudel, Rhipsalis cereuscula Haworth, Parodia ottonis (Lehmann) N.P. Taylor, Parodia haselbergii (Haage ex. Ruempler) Brandt e Opuntia monacantha Haworth.
\end{abstract}

Palavras-chave: Cactaceae, diversidade, Bacia Hidrográfica do Rio Taquari, levantamento

\begin{abstract}
Cactaceae family in Taquari river Hydrological Basin, RS, Brazil). The survey on the species of Cactaceae family in Rio Taquari Hydrological Basin, RS, Brazil was carried out in order to know the diversity and the distribution of species in the studied area, once there is no data on Cactaceae family in this region. Eleven species were found, distributed in five genera: Cereus hildmannianus K. Schumann, Lepismium cruciforme (Vellozo) Miquel, Lepismium warmingianum (K. Schumann) Barthlott, Lepismium houlletianum (Lemaire) Barthlott, Lepismium lumbricoides (Lemaire) Barthlott, Rhipsalis floccosa ssp. pulvinigera (G.A. Lindberg) Barthlott \& N.P. Taylor, Rhipsalis teres (Vellozo) Steudel, Rhipsalis cereuscula Haworth, Parodia ottonis (Lehmann) N.P. Taylor, Parodia haselbergii (Haage ex. Ruempler) Brandt and Opuntia monacantha Haworth.
\end{abstract}

Key words: Cactaceae, diversity, Rio Taquari Hydrological Basin, survey

\section{Introdução}

A Bacia Hidrográfica do Rio Taquari pertence ao sistema Taquari-Antas que se situa na região nordeste do Estado do Rio Grande do Sul, abrangendo área de $26.428 \mathrm{~km}^{2}$ (Magma Eng. 1997), podendo ser considerada uma área extremamente representativa da flora riograndense, uma vez que apresentava originalmente uma riquíssima cobertura vegetal (Reitz et al. 1983), inserida em sua maior parte, na Formação da Floresta Estacional Decidual, cuja estrutura permite a implantação de muitos grupos de vegetais epífitos (Teixeira et al. 1986).

A família Cactaceae é um destes grupos vegetais que no Rio Grande do Sul, pode ser encontrado principalmente associado às formações vegetais ou em afloramentos rochosos. Trabalhos florísticos de Brack et al. (1985), Waechter (1986), Dislich \& Mantovani (1998) citam espécies da família tipicamente florestais. O trabalho de Taylor \& Zappi (1991) cita espécies rupestres encontradas em paredões e rochas.
A família possui cerca de 1.300 espécies distribuídas nas regiões tropicais do Novo Mundo (Hunt 1999), sendo no Rio Grande do Sul, representada por aproximadamente 80 espécies e 12 gêneros (Larocca, comunic. pessoal). Possui como característica o alto grau de evolução, tanto na morfologia vegetativa, como na estrutura floral, adaptando-se para a polinização (Barthlott \& Hunt 1993).

Assim, visando conhecer a flora Cactaceae ocorrente na Bacia Hidrográfica do Rio Taquari, o presente trabalho tem como objetivo realizar um estudo taxonômico dos gêneros e espécies encontrados na área, além de fornecer subsídios para futuros trabalhos de conservação vegetal.

\section{Material e métodos}

Para o levantamento das espécies e obtenção de material para análise, foram realizadas coletas em diferentes áreas na Bacia Hidrográfica do Rio Taquari, no período de agosto/2000 a agosto/2002. Foram

\footnotetext{
1 Universidade do Vale do Taquari, UNIVATES, Setor de Botânica e Paleobotânica, Museu de Ciências Naturais, Rua Avelino Tallini, 171, CEP 95900-000, Lajeado, RS, Brasil (sbp_mcn@univates.br)

2 Autor para correspondência: julianebruxel@bol.com.br
} 
realizados registros sobre as espécies, coleta de um exemplar depositado em herbário e de um exemplar para cultivo em viveiro.

O Rio Taquari nasce no extremo leste do Planalto dos Campos Gerais, com a denominação de Rio das Antas, até a confluência com o Rio Guaporé, nas imediações da cidade de Muçum. A partir daí passa a denominar-se Taquari, desembocando no Rio Jacuí, junto à cidade de Triunfo. O Rio Taquari percorre $140 \mathrm{~km}$ e seus principais afluentes pela margem esquerda são os arroios Boa Vista e Estrela e pela margem direita os rios Guaporé, Forqueta e Taquari-Mirim.

Os exemplares coletados foram herborizados seguindo as técnicas propostas por Fidalgo \& Bononi (1989), Jasper et al. (1997) e encontram-se depositados e registrados no Herbário do Museu de Ciências Naturais da UNIVATES (HUNIVATES) ou são mantidos no viveiro junto ao Jardim Botânico de Lajeado (JBL), para posterior estudo.

A identificação das espécies foi obtida a partir da comparação com ilustrações e descrições a partir dos trabalhos de Scheinvar (1985), Lombardi (1991, 1995), Tamashiro \& Zickel (1991), Barthlott \& Taylor (1995) e Hunt (1999). Além disso, foram realizadas visitas ao herbário PACA do Instituto Anchietano de Pesquisas em São Leopoldo (RS), para confirmação taxonômica das espécies estudadas.

\section{Resultados e discussão}

A família Cactaceae é representada por plantas perenes, geralmente suculentas e altamente especializadas, apresentando um alto grau de evolução paralela em morfologia vegetativa e na estrutura floral (Barthlott \& Hunt 1993). Apresentam hábito arbóreo, arbustivo, epifítico ou geófito. Caule colunar, cilíndrico, globoso, tuberculado, com costelas, alado ou achatado, freqüentemente segmentado, geralmente sem folhas e com espinhos, esverdeado e com função fotossintetizante. Folhas, quando presentes, arranjadas espiraladamente, simples, inteiras e sem estípulas. Gemas axilares desenvolvendo um indumento de tricomas multicelulares (aréola) e folhas geralmente transformadas em espinhos. Aréolas originadas de ramos reduzidos e modificados de onde surgiram tricomas, espinhos e flores. Flores geralmente vistosas, isoladas ou raramente agrupadas, usualmente sésseis nas aréolas, quase sempre bissexuais, usualmente actinomorfas; receptáculo envolvendo o ovário (pericarpelo), glabro ou revestido com escamas bractiformes e aréolas; aréolas com tricomas, pêlos e/ ou espinhos; tépalas usualmente numerosas, em séries graduais; estames freqüentemente numerosos em uma ou mais séries de disposição espiralada, inseridos no tubo floral, anteras biloculares, tetrasporangiadas, com deiscência longitudinal; ovário ínfero (exceto espécies de Pereskia), unilocular, carpelos de 3 a 20, óvulos numerosos, estilete geralmente longo, estigma com 3 a 20 lóbulos. Fruto carnoso ou seco, glabro, escamoso, tomentoso, cerdoso ou espinhoso, deiscente ou indeiscente. Sementes numerosas, endosperma ausente ou presente; cotilédones reduzidos ou vestigiais (Barthlott \& Hunt 1993).

No levantamento realizado em áreas da Bacia Hidrográfica do Rio Taquari foram encontradas e identificadas 11 espécies da família Cactaceae distribuídas em cinco gêneros apresentados a seguir, com a descrição e notas sobre a biologia das espécies observadas, bem como a chave dicotômica das espécies ocorrentes na área.

Chave para identificação das espécies de Cactaceae na Bacia Hidrográfica do Rio Taquari, RS, Brasil

1. Caule segmentado, com artículos

2. Plantas pendentes, epífitas ou rupícolas

3. Ramificação mesotônica

4. Artículos cilíndricos .

4. L. lumbricoides

4. Artículos angulados e/ou aplanados

5. Artículos angulados, com 3-5 costelas

2. L. cruciforme

5. Artículos aplanados, sem costelas

6. Margem dos ramos crenada

5. L. warmingianum

6. Margem dos ramos serreada

3. L. houlletianum

3. Ramificação acrotônica e dicotômica

7. Artículos cilíndricos; aréolas com escama triangular e/ou cerdas

8. Flores laterais ou terminais

11. R. teres

8. Flores terminais ou subterminais 9. $R$. cereuscula 
7. Artículos cilíndricos com angulado descontínuo; aréolas em proeminências

10. R. floccosa ssp. pulvinigera

2. Plantas eretas, arbóreas ou arbustivas

9. Plantas com cladódios articulados, colunares, 6-9 costelas

1. C. hildmannianus

9. Plantas com cladódios achatados, obovados a lanceolados

6. O. monacantha

1. Caule globoso, sem artículos

10. Plantas com flores vermelho-alaranjadas

7. P. haselbergii

10. Plantas com flores amarelas 8. P. ottonis

1. Cereus hildmannianus K. Schumann, in Martius, Fl. Brasiliensis 4(2): 202 (1890).

Fig. 1.

Planta ereta, colunar, arbórea ou arbustiva, terrícola, rupícola e eventualmente epífita, de até 8 metros de altura. Cladódios articulados com constrições de crescimento características; coloração geralmente verde. Costelas 6-9; aréolas inclusas com tomento cinza. Espinhos 5-10, radiais, rígidos, castanhos a pretos. Flores campanuladas com 10-18cm compr., segmentos externos do perianto crassos, verdosos com ápice avermelhado; estames numerosos, estilete cilíndrico; estigma com 12 lóbulos. Fruto carnoso, oval-alongado, amarelo quando maduro, estilete persistente e deiscente por fenda lateral. Sementes obovadas e pretas.

Espécie com distribuição no Paraguai, Bolívia, Uruguai, Argentina e Brasil. Segundo Schumann (1890) e Scheinvar (1985), existem registros para São Paulo, Rio de Janeiro e ainda região sul do Brasil. Na Bacia Hidrográfica do rio Taquari pode ser encontrada em áreas rochosas, solos pedregosos, em locais abertos e sob a mata. Foi encontrada na forma epífita, desenvolvendo-se normalmente sobre troncos de árvores. Ocorre tanto na região alta, nos municípios de Guaporé, Ilópolis, São José do Herval, como na região baixa, nos municípios de Capitão, Travesseiro, Lajeado. Sua floração pode ser registrada principalmente nos meses de outubro a janeiro e sua frutificação se estende pelo mesmo período.

Material selecionado: BRASIL. Rio Grande do Sul: São José do Herval, 13/I/2002, fl., E. Freitas, 894 (HUNIVATES).

2. Lepismium cruciforme (Vellozo) Miquel, Bull. Sci. Phys. Néerl 1: 49 (1838).

Fig. 2.

Planta epífita, pendente, de ramificação mesotônica, com até $1 \mathrm{~m}$ de comprimento. Artículos angulados com 3-5 costelas, oblongos, alados, coloração variando do verde ao vermelho, conforme a insolação recebida. Aréolas imersas, com presença de pêlos abundantes de até $5 \mathrm{~mm}$ compr., cinzentos a brancos. Flores laterais, solitárias ou em curta inflorescência, emersas na aréola, $0,7-1,3 \mathrm{~cm}$ compr., cor creme, branca a rosada, tépalas 10 ; estilete emergente, róseo-avermelhado, estigma com 2-6 lóbulos. Fruto baga, vermelho-brilhante, de 5-7mm diâm. Sementes pretas, numerosas e obovadas.

Espécie de distribuição no Paraguai, Argentina e Brasil, nos Estados de Pernambuco, Bahia, Minas Gerais, Espírito Santo, Rio de Janeiro, São Paulo, Mato Grosso do Sul, Paraná, Santa Catarina e Rio Grande do Sul (Barthlott \& Taylor 1995).

Possui distribuição ampla e uniforme em toda a bacia, apresentando hábito principalmente epifítico. Adapta-se a diferentes níveis de luminosidade, apresentando alterações fisiológicas como caule avermelhado e maior pilosidade nas aréolas quando exposta em excesso a esse fator ambiental.

Sua floração pode ser registrada principalmente nos meses de outubro a janeiro, com frutificação ocorrendo no mesmo período.

Material selecionado: BRASIL. Rio Grande do Sul: Ilópolis, 18/XI/2000, fl., E. Freitas, E. Musskopf e $J$. Bruxel 513 (HUNIVATES); São José do Herval, 4/II/2001, fl., E. Freitas, J. Bruxel e T. Klein 596 (HUNIVATES); Lajeado, 2/IX/01, fl., J. Spellmeir 823 (HUNIVATES).

3. Lepismium houlletianum (Lemaire) Barthlott, Bradleya 5: 99 (1987).

Fig. 3.

Planta epífita, pendente, ramificação mesotônica. Artículos aplanados e muito ramificados; ramos elípticos a lanceolados com base constricta, geralmente até a metade, cerca de $23 \mathrm{~cm}$ compr. e $3,5 \mathrm{~cm}$ larg.; margem dos ramos profundamente serreada. Aréola emersa nas margens, com escama triangular, com pêlos curtos e escassos. Flores campanuladas, laterais e numerosas, 1,5-2,0 cm compr., cor creme a branca; tépalas desiguais entre si, as mais externas triangulares e as internas elípticas; estames 26-40, desiguais entre 
si, base dos estames avermelhada, anteras brancas, estigma trilobado. Fruto baga, globoso, castanho-avermelhado, cerca $0,8 \mathrm{~cm}$ diâm. Sementes sub-oblongas, castanho-avermelhadas.

Espécie de distribuição na Argentina e Brasil, nos Estados de Minas Gerais, Espírito Santo, Rio de Janeiro, São Paulo, Paraná, Santa Catarina e Rio Grande do Sul (Barthlott \& Taylor 1995).

Na Bacia Hidrográfica do Rio Taquari, apresentase geralmente como epífita, em praticamente todas as áreas de estudo, destacando principalmente locais sombreados e com certa umidade. É planta fácil de distinguir das demais espécies, por apresentar seus ramos com bordas profundamente serreadas.

Sua floração pode ser observada nos meses de novembro a janeiro, com frutificação ocorrendo ao longo do mesmo período, sendo que existem dados em trabalhos realizados, que registram sua floração ao longo de todo o ano.

Material selecionado: BRASIL. Rio Grande do Sul: Lajeado, 9/IX/2000, fl., E. Freitas, E. Musskopf e J. Bruxel 305 (HUNIVATES); Imigrante, 11/VII/2002, fl., J. Bruxel, E. Freitas e E. Santos 957 (HUNIVATES).

\section{Lepismium lumbricoides (Lemaire) Barthlott, Bradleya 5: 99 (1987).}

Fig. 4.

Planta epífita, pendente. Artículos cilíndricos, ramificação mesotônica. Aréolas emersas, com escamas cordiformes e caducas. Flores campanuladas, laterais, abundantes, cerca $1,5 \mathrm{~cm}$ compr., cor branca a amarelada; tépalas 11-16, desiguais entre $\mathrm{si}$, as mais externas triangulares e as mais internas elíptico-lanceoladas até obovadas; estames 28-38, filetes esverdeados, anteras brancas; estigmas com 3-4 lobos, brancos, papilosos. Fruto baga, elipsóide, sem apêndices ou com escamas cordiformes, cerca $0,4 \mathrm{~cm}$ diâm., vermelho. Sementes elípticas a subovaladas, pretas.

Espécie de distribuição na Argentina, Paraguai, Uruguai e Brasil, nos Estados de São Paulo, Paraná, Santa Catarina e Rio Grande do Sul (Barthlott \& Taylor 1995). É encontrada em praticamente toda a área da Bacia Hidrográfica do Rio Taquari.

Freqüentemente se fixa em mais de um ponto através de suas raízes adventícias. Sua floração pode ser registrada principalmente nos meses de agosto a dezembro e sua frutificação ocorre no mesmo período.

Material selecionado: BRASIL. Rio Grande do Sul: Arroio do Meio, 2/X/2000, fl., J. Bruxel 405
(HUNIVATES); Santa Clara do Sul, 9/XI/2002, fl., J. Bruxel 1054 (HUNIVATES).

5. Lepismium warmingianum (K. Schumann) Barthlott, Bradleya 5: 99 (1987).

Fig. 5.

Planta epífita, pendente. Artículos aplanados com cerca de $23 \mathrm{~cm}$ compr. e $2 \mathrm{~cm}$ larg., lanceolados com a margem dos ramos crenada, lenhosa, com ramificação mesotônica. Aréolas emersas nas crenas, pêlos curtos e escassos com 1-2 cerdas, com escamas triangulares. Flores laterais, isoladas, campanuladas, cerca $1,5 \mathrm{~cm}$ compr., cor branca a amarelada; tépalas 11-15, desiguais entre si, as mais externas triangulares e as internas fusiformes a lanceoladas; estames 25-35, inseridos em elevação em volta do estilete. Fruto baga, globoso, restos de perianto persistentes, cerca $1 \mathrm{~cm}$ diâm., coloração avermelhada a negra. Sementes subelípticas, negras.

Espécie de distribuição na Argentina, Paraguai e Brasil, nos Estados de Minas Gerais, Espírito Santo, Rio de Janeiro, São Paulo, Mato Grosso do Sul, Paraná, Santa Catarina e Rio Grande do Sul (Barthlott \& Taylor 1995).

Apresenta hábito bastante semelhante ao da espécie L. houlletianum (Lemaire) Barthlott. Sua floração pode ser registrada principalmente nos meses de setembro a dezembro e sua frutificação ocorre no mesmo período.

Material selecionado: BRASIL. Rio Grande do Sul: São José do Herval, 31/VIII/2001, fl., J. Bruxel 818 (HUNIVATES); Ilópolis, 30/VIII/2001, fl., E. Musskopf e C. Gonçalves 822 (HUNIVATES).

6. Opuntia monacantha (Willdenow) Haworth, Sup. Plan. Suc. 81 (1819).

Fig. 6.

Planta arbustiva, ereta, suculenta, de até 1,5m alt., provida de aréolas espinescentes. Cladódios achatados, obovados a lanceolados. Aréola 3-7mm diâm., com 1-3 espinhos, cinzentos. Flores solitárias, amarelas, $6-9 \mathrm{~cm}$ compr.; segmentos do perianto externos crassos, purpúreos, os internos lanceolados, membranáceos, amarelos; anteras amarelas, estigma 5-7 lobado. Fruto seco, piriforme, vistoso, cerca de $6-7 \mathrm{~cm}$ compr. Semente amarelada, cerca $0,5 \mathrm{~cm}$ compr.

Espécie de distribuição na Argentina, Paraguai, Uruguai e na costa sudeste/sul do Brasil. Na Bacia Hidrográfica do Rio Taquari foi encontrada em algumas áreas de estudo, nos municípios de São José do Herval e em Tabaí. Sua floração pode ser registrada 
nos meses outubro a dezembro, sendo que a sua frutificação se estende até fevereiro.

Material selecionado: BRASIL. Rio Grande do Sul: São José do Herval, 26/X/2001, fl., E. Musskopf 844 (HUNIVATES).

7. Parodia haselbergii (Haage ex Ruempler) Brandt, An. Soc. Cient. Arg. 96: 70 (1923).

Fig. 7.

Plantas isoladas, $4-15 \mathrm{~cm}$ diâm., esféricodepressas a esféricas. Caule globoso com costelas em número de 30-60. Aréolas um pouco imersas, distantes 4-6mm entre si, cerca de 25-60 espinhos, cerdosos a aciculares, com cerca de $1,5 \mathrm{~cm}$ compr., brancotransparentes, cobrindo densamente o caule, com $10 \mathrm{~mm}$ compr. ou mais. Flores vermelho-alaranjadas brilhantes, agrupadas no ápice do caule; segmentos internos do perianto permanecendo eretos e circundando o estilete; estames inclusos. Fruto seco, esférico a curto-oblongo, com cerca de $10 \mathrm{~mm}$ compr., cerdoso, branco a amarelado. Sementes pretas, fortemente tuberculadas.

Espécie de distribuição no sudeste de Santa Catarina e Rio Grande do Sul (Larocca, comunic.
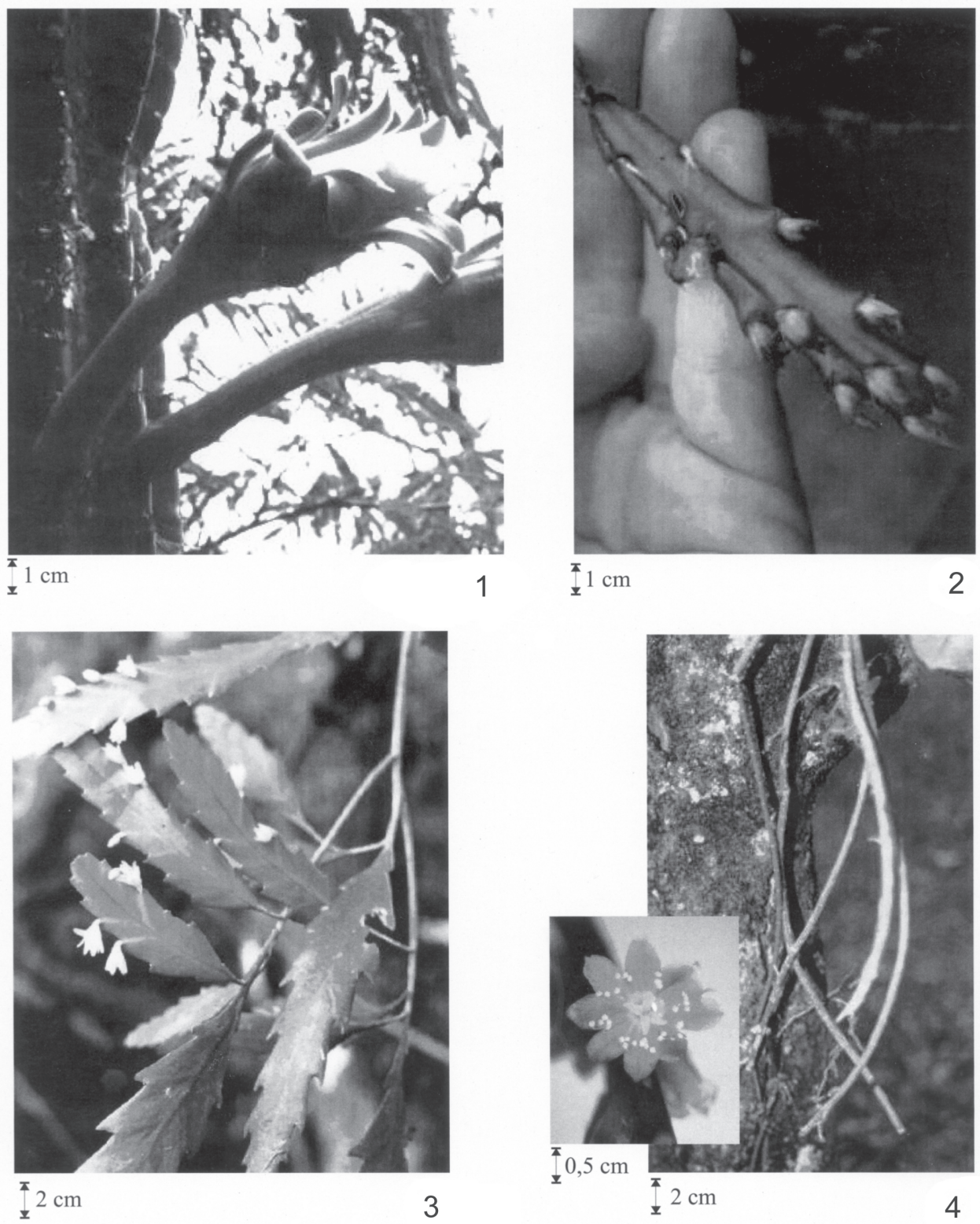

Figuras 1-4. 1. Cereus hildmaniannus K. Schumann, 2. Lepismium cruciforme (Vellozo) Miquel, 3. Lepismium houlletianum (Lemaire) Barthlott, 4. Lepismium lumbricoides (Lemaire) Barthlott, com detalhe da flor. 
pessoal). Na Bacia Hidrográfica do Rio Taquari, foi observada em três áreas de estudo, nos municípios de Forquetinha, Guaporé e Putinga. Apresenta hábito rupícola e foi encontrada em afloramentos rochosos praticamente verticais. Sua floração ocorre principalmente nos meses outubro a dezembro.

Material selecionado: BRASIL. Rio Grande do Sul: Guaporé, 23/VII/2002, fl., J. Bruxel e F. Neuls 957 (HUNIVATES); Putinga, 18/X/2002, fl., J. Santos 1000 (HUNIVATES).

8. Parodia ottonis (Lehmann) N. P. Taylor, Bradleya 5: 93 (1987).

Fig. 8.

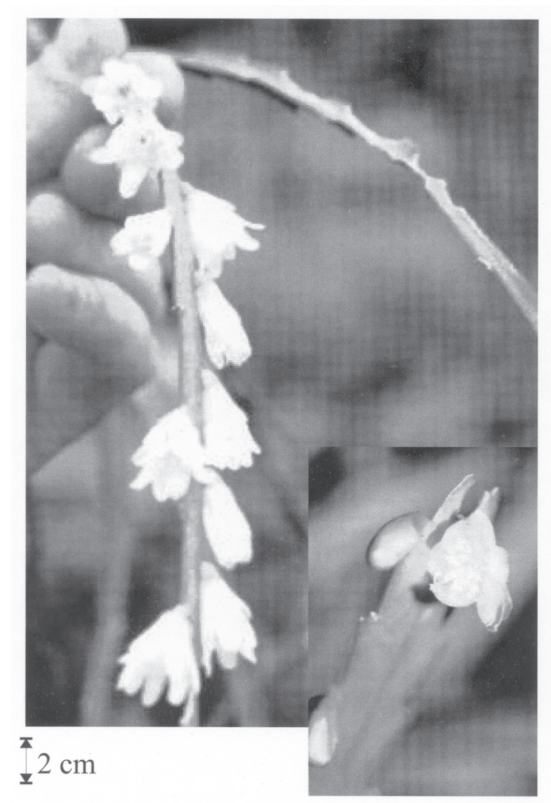

5

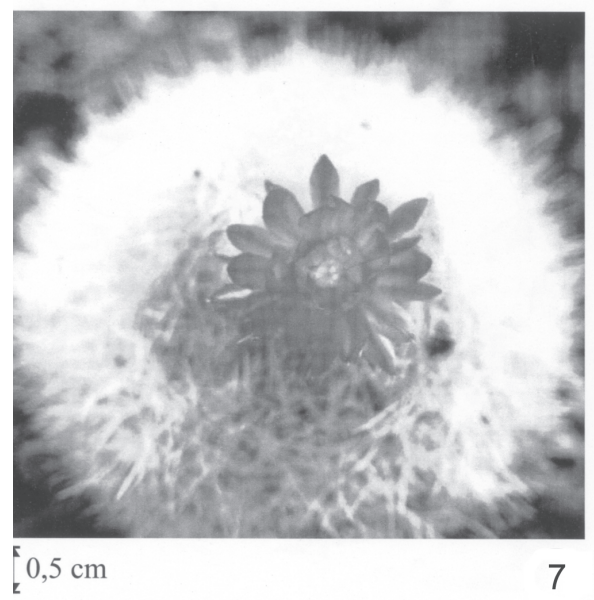

Planta depresso-globosa com base quase cônica de $5-7 \mathrm{~cm}$ de diâm., ápice ligeiramente imerso. Caule globoso; costelas 6-15, pouco marcadas. Aréolas imersas, distantes $10-15 \mathrm{~mm}$ entre si, circulares, a transversalmente elípticas, com lã branca, curta ou larga; espinhos radiais $8-12$, retos ou pouco sinuosos, de 8-15mm compr., marrom-amarelados a avermelhados. Flores amarelas, 2-4 na aréola superior; segmentos do perianto bisseriados, oblongos, com ápice apiculado; estames inclusos, filetes unidos à base dos segmentos interiores do perianto, estigma amarelo, com lobos amarelos a vermelhos. Fruto seco, avermelhado, deiscente. Sementes castanhas, apresentando segundo Scheinvar (1985), cerca de 1,2mm compr. e 0,7mm larg.
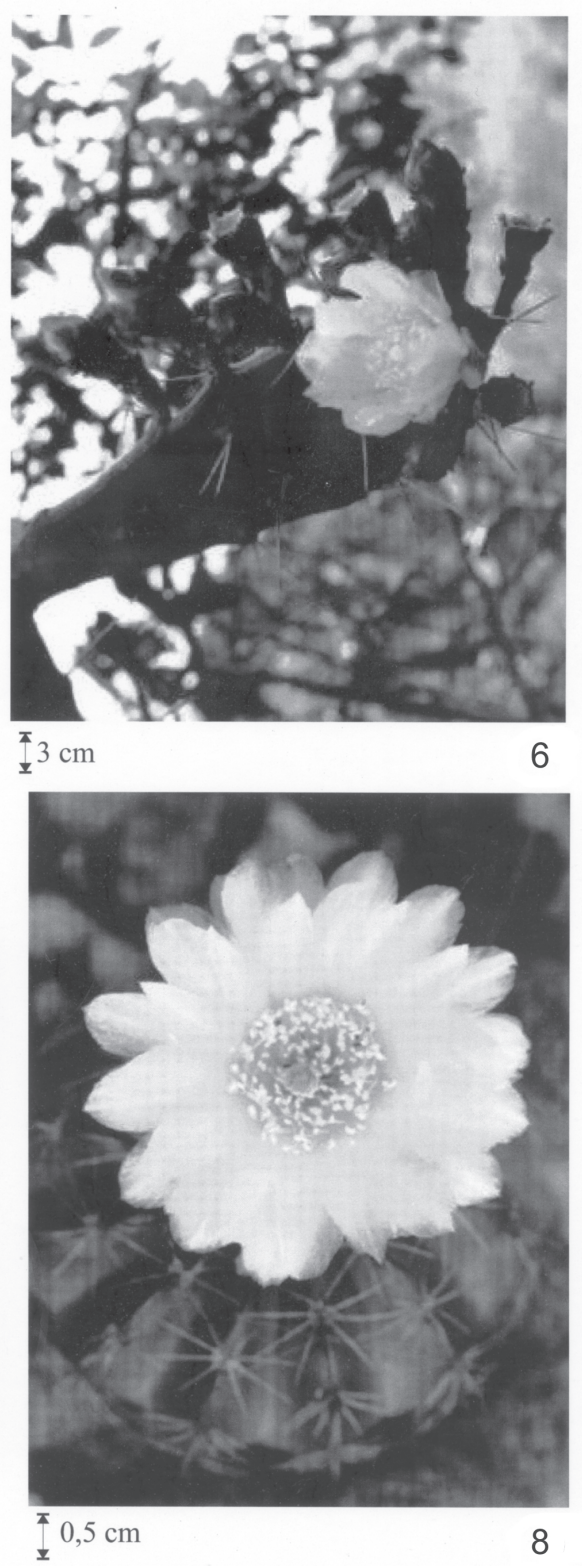

Figuras 5-8. 5. Lepismium warmingianum (K. Schumann) Barthlott, com detalhe da flor, 6. Opuntia monacantha (Willdenow) Haworth, 7. Parodia haselbergii (Haage ex Ruempler) Brandt, 8. Parodia ottonis (Lehmann) N.P. Taylor. 
Espécie de distribuição na Argentina, Paraguai, Uruguai e no Brasil (Hunt 1999). Na bacia hidrográfica, foi encontrada em apenas uma área de estudo, no município de São José do Herval. Apresenta hábito rupícola, ocorrendo num afloramento rochoso, exposto ao sol, ao lado do arroio Forqueta. Sua floração foi registrada nos meses de outubro e novembro, com frutificação em dezembro.

Material selecionado: BRASIL. Rio Grande do Sul: São José do Herval, 3/XI/2002, fl., J. Bruxel 1050 (HUNIVATES).

9. Rhipsalis cereuscula Haworth, Phil. Mag. 7: 112 (1830).

Planta epífita ou rupícola, pendente. Artículos cilíndricos, sendo os primeiros mais compridos (10-30 cm compr. e 3-4mm diâm.) e os secundários curtos (7-10cm compr. e 3-4mm diâm.), sendo que os terminais congestos e mais ramificados; ramificação inicialmente dicotômica passando a acrotônica; coloração verde-amarela. Aréolas emersas, escamas triangulares diminutas, 2-4 cerdas curtas, sendo estas mais abundantes no ápice dos ramos curtos. Flores campanuladas, terminais ou subterminais, brancas; tépalas 17-19, desiguais entre si; estames 54-55, desiguais entre si, anteras branco-rosadas; estilete branco, central, estigmas com 4-5 lobos. Fruto baga, globoso, obovóide, cerca $0,6 \mathrm{~cm}$ diâm., branco com escamas avermelhadas. Sementes fusiformes, castanho-claras até escuras.

Espécie de distribuição na Bolívia, Argentina, Paraguai, Uruguai e Brasil, no nordeste de Pernambuco, sudeste da Bahia, sul de Minas Gerais, leste do Rio de Janeiro, São Paulo, sul do Mato Grosso do Sul, Paraná, Santa Catarina e Rio Grande do Sul (Barthlott \& Taylor 1995).

Na Bacia Hidrográfica do Rio Taquari, possui distribuição bastante restrita, sendo encontrada apenas nos municípios de Lajeado e Forquetinha. Sua floração pode ser registrada nos meses de setembro a novembro e sua frutificação se estende até janeiro.

Material selecionado: BRASIL. Rio Grande do Sul: Lajeado, 9/IX/2000, fl., E. Freitas, E. Musskopf e $J$. Bruxel 304 (HUNIVATES).

10. Rhipsalis floccosa ssp. pulvinigera (G.A. Lindberg) Barthlott. \& N.P. Taylor, Gartenflora. 38: 184 (1889).

Fig. 9.

Planta epífita, pendente. Artículos cilíndricos com angulado descontínuo (irregulares na espessura), geralmente de 40-70cm compr. e 4-7mm diâm., verdeclaros, com ramificação acrotônica e dicotômica. Artículos com aréolas cavernosas, emersas em pequenas proeminências, presença de pêlos brancocinzentos no interior das aréolas. Flores laterais, com cerca de 1,2cm compr.; tépalas desiguais entre si, sendo as externas triangulares e as internas mais elípticas; estames desiguais, anteras brancas; estigma com 4-5 lobos. Fruto baga, esférico, cerca $0,6 \mathrm{~cm}$ diâm., cor violácea. Sementes reniformes, negras.

Espécie de distribuição no sul e sudeste do Brasil, nos Estados de Minas Gerais, Espírito Santo, Rio de Janeiro, São Paulo, Paraná, Santa Catarina e Rio Grande do Sul. Do litoral atlântico até florestas estacionais, podendo ser encontrada a até $1.800 \mathrm{~m}$ de altitude (Barthlott \& Taylor 1995).

Na Bacia Hidrográfica do Rio Taquari, possui distribuição restrita nas áreas de estudo, sendo encontrada apenas na região alta, nos municípios de São José do Herval, Putinga, Ilópolis e Sério. Espécie caracterizada por apresentar artículos avermelhados quando exposta à incidência solar. Sua floração pode ser registrada nos meses de outubro a dezembro e sua frutificação se estende até janeiro.

Material selecionado: BRASIL. Rio Grande do Sul: Ilópolis, 11/XI/2000, fl., J. Bruxel, E. Freitas e E. Musskopf 511 (HUNIVATES); São José do Herval, 6/X/2001, fl., T. Klein 843 (HUNIVATES).

11. Rhipsalis teres (Vellozo) Steudel, Nom., Bot. ed. II 2: 449 (1841).

Fig. 10.

Planta epífita, pendente. Artículos cilíndricos, verdes, com até $50 \mathrm{~cm}$ compr., apresentam ramificação acrotônica e dicotômica. Aréolas emersas com pequenas escamas triangulares. Flores terminais e laterais, com até $1,2 \mathrm{~cm}$ compr., perpendiculares em relação ao eixo dos artículos, amareladas e abertas; perianto campanulado; tépalas desiguais, sendo as externas triangulares e as internas elípticas; estames desiguais, anteras basifixas, brancas; estilete esverdeado; estigma com 3-5 lobos. Fruto baga, depresso-globoso, $0,5 \mathrm{~cm}$ diâm., branco, translúcido. Sementes reniformes, cor castanha.

Espécie de distribuição no Brasil, nos Estados de Minas Gerais, Rio de Janeiro, São Paulo, Paraná, Santa Catarina e Rio Grande do Sul (Barthlott \& Taylor 1995).

Na Bacia Hidrográfica do Rio Taquari, possui ampla distribuição ocorrendo em toda a área de estudo, 

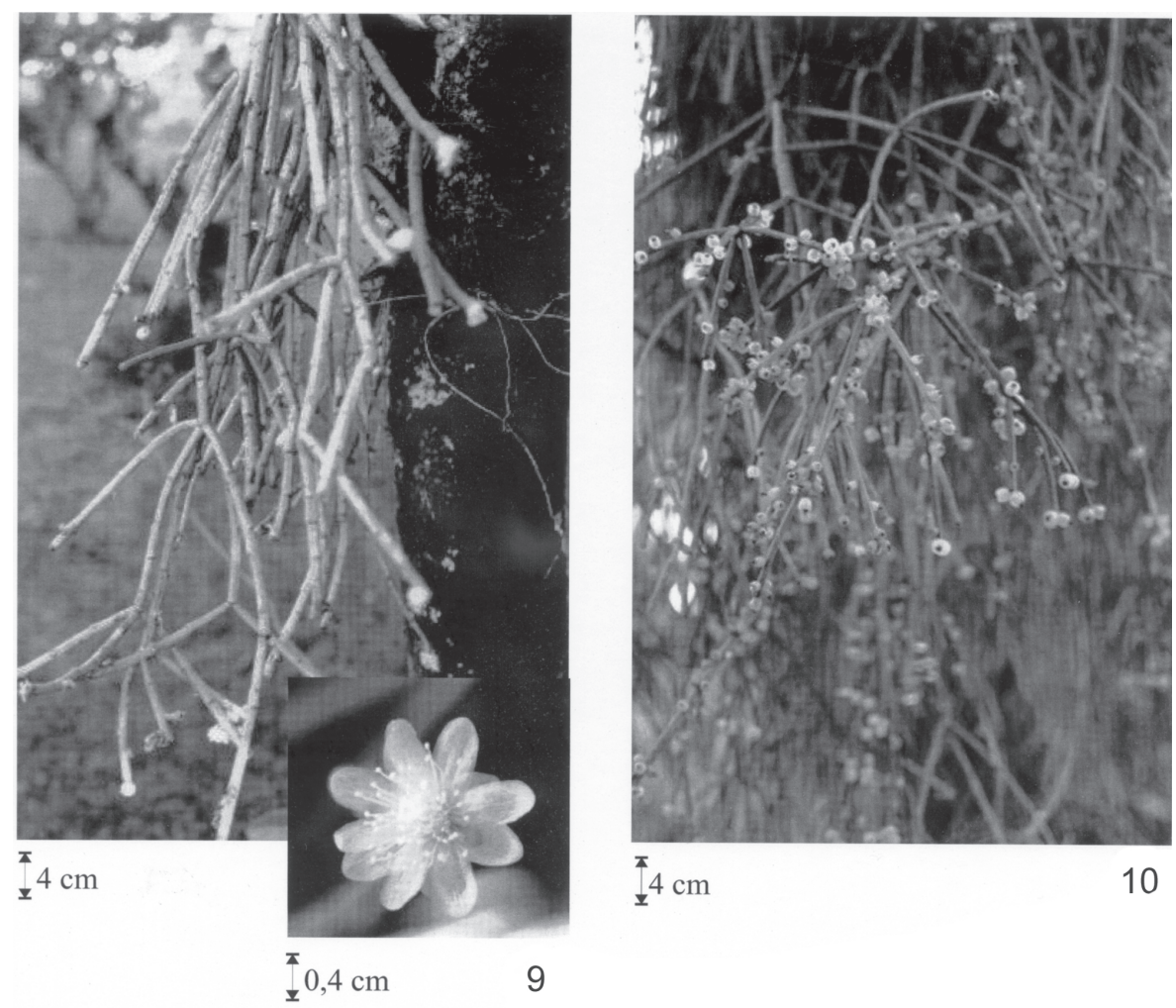

Figuras 9-10. 9. Rhipsalis floccosa ssp. pulvinigera (G.A. Lindberg) Barthlott \& N.P. Taylor, com detalhe da flor, 10. Rhipsalis teres (Vellozo) Steudel.

desde a região baixa no município de Lajeado até a região alta no município de Ilópolis. Sua floração pode ser registrada nos meses de junho a setembro e sua frutificação se estende até dezembro, sendo encontrados exemplares em fruto no mês de março.

Material selecionado: BRASIL. Rio Grande do Sul: São José do Herval, 23/III/2001, fl., E. Freitas, E. OMusskopf e J. Bruxel 624 (HUNIVATES); Forquetinha, 30/VI/2001, fl., E. Musskopf e J. Bruxel 786 (HUNIVATES).

A ocorrência de 11 espécies em 33 pontos de estudo distribuídos em 27 municípios na Bacia Hidrográfica do Rio Taquari pode ser considerada como indicativo de elevado número de espécies para a família Cactaceae. Porém, tendo em vista que algumas áreas da bacia hidrográfica ainda não foram avaliadas, certamente esse número poderá ser ampliado com a realização de novas coletas em outras áreas de estudo.

\section{Agradecimentos}

Aos colegas pesquisadores Elisete M. de Freitas e Emerson L. Musskopf, bolsistas Emília dos Santos e
Toni F. Klein, voluntárias Jaqueline Spellmeier e Josiéle dos Santos, companheiros nas constantes saídas de campo realizadas; ao colega Rafael Jair Gonçalves, pela elaboração das pranchas; à UNIVATES Centro Universitário, pelo financiamento da pesquisa; ao Departamento de Florestas e Áreas Protegidas (DEFAP) da Secretaria Estadual de Meio Ambiente do Rio Grande do Sul, pela licença de coleta cedida à equipe de trabalho; ao professor João Larocca, que colaborou na identificação de espécies.

\section{Referências bibliográficas}

Barthlott, W. \& Hunt, D.R. 1993. Cactaceae. In: Kubitzki, K. The families and genera of vascular plants. 2: 161-197. Berlin, Springer.

Barthlott, W. \& Taylor, N.P. 1995. Notes towards a Monograph of Rhipsalideae (Cactaceae). Bradleya 13: 43-79.

Brack, P.; Bueno, R.M.; Falkenberg, D.B.; Paiva, M.R.C.; Sobral, M. \& Stehmann, J.R. 1985. Levantamento florístico do Parque Estadual do Turvo, Tenente Portela, Rio Grande do Sul, Brasil. Rossléria 7(1): 69-94.

Dislich, R. \& Mantovani, W. 1998. A Flora de epífitas vasculares da reserva da cidade universitária "Armando de Salles Oliveira" (São Paulo, Brasil). Boletim de Botânica da Universidade de São Paulo 17: 61-83. 
Fidalgo, O. \& Bononi, V.L.R. 1989. Técnicas de coleta, preservação e herborização de material botânico. São Paulo, Instituto de Botânica, SP.

Jasper, A.; Musskopf, E.L. \& Majolo, M.A. 1997. Manual para Preparação de Material de Apoio Didático para Aulas Práticas na área de Ciências e Biologia. UNIVATES. Lajeado, Rio Grande do Sul.

Hunt, D. 1999. CITES Cactaceae Chechlist, ed. 2. Zürich, Royal Botanic Gardens, Kew and International Organization for the Study of Suculent Plants.

Lombardi, J.A. 1991. O gênero Rhipsalis Gärtner (Cactaceae), no estado de São Paulo I. Espécies com ramos cilíndricos ou subcilíndricos. Acta Botanica Brasilica 5(2): 53-76.

Lombardi, J.A. 1995. O gênero Rhipsalis Gärtner (Cactaceae), no estado de São Paulo II. Espécies com ramos aplanados. Acta Botanica Brasilica 9(1): 151-161.

Magma Engenharia Ltda. 1997. Avaliação qualiquantitativa das disponibilidades e demandas de água na Bacia Hidrográfica do sistema Taquari-Antas. Relatório técnico n.1, Cenário atual da Bacia Hidrográfica do sistema Taquari-Antas. v.1.
Reitz, R.; Klein, R.M. \& Reis, A. 1983. Projeto Madeira do Rio Grande do Sul. Itajaí, Herbário Barbosa Rodrigues. Scheinvar, L. 1985. Cactáceas. Flora Ilustrada Catarinense. Fascículo CACT: 1-383.

Schumann, K. 1890. Cactaceae. In: C.F.P. Martius \& A.G. Eichler (eds.). Frid. Fleischer in Comm. Flora Brasiliensis 4(2): 186-334.

Tamashiro, J.Y. \& Zickel, C.S. 1991. Flora Fanerogâmica da Reserva do Parque Estadual das Fontes do Ipiranga (São Paulo, Brasil). Hoehnea 18(2): 137-141.

Taylor, N.P. \& Zappi, D.C. 1991. Cactaceae do Vale do Rio Jequitinhonha. Acta Botanica Brasilica 5(1): 63-69.

Teixeira, M.B.; Loura-Neto, A.B.; Pastore, U. \& Rangel Filho, A.L.R. 1986. Vegetação; as regiões fitoecológicas, suas naturezas, seus recursos econômicos; estudo fitogeográfico. Pp. 541-632. In: Levantamento de Recursos Naturais. Rio de Janeiro, Instituto Brasileiro de Geografia e Estatística, v. 33.

Waechter, J.L. 1986. Epífitos Vasculares da Mata Paludosa do Faxinal, Torres, Rio Grande do Sul, Brasil. Iheringia sér. Bot. 34: 39-49. 